\title{
Brain dead or not? CT angiogram yielding false-negative result on brain death confirmation
}

\author{
Robyn Johnston, ${ }^{1}$ Chandrasekaran Kaliaperumal, ${ }^{2}$ Gerald Wyse, ${ }^{3}$ George Kaar ${ }^{1}$
}

${ }^{1}$ Department of Neurosurgery, Cork University Hospital, Cork, Ireland

${ }^{2}$ Department of Paediatric Neurosurgery, Children's University Hospital, Temple Street, Dublin, Ireland ${ }^{3}$ Department of

Neuroradiology, Cork University Hospital, Cork, Ireland

\section{Correspondence to}

Chandrasekaran Kaliaperumal, ckaliaperumal@gmail.com
To cite: Johnston $\mathrm{R}$ Kaliaperumal C, Wyse G, et al. BMJ Case Reports [please include Day Month Year] doi:10.1136/bcr-2012007754

\section{SUMMARY}

We describe a case of severe traumatic brain injury with multiple facial and skull fractures where $\mathrm{CT}$ angiogram (CTA) failed to yield a definite result of brain death as an ancillary test. A 28-year-old man was admitted following a road traffic accident with a Glasgow Coma Score (GCS) of 3/15 and fixed pupils. CT brain revealed uncal herniation and diffuse cerebral oedema with associated multiple facial and skull fractures. $72 \mathrm{~h}$ later, his clinical condition remained the same with high intracranial pressure refractory to medical management. Clinical confirmation on brain death was not feasible owing to facial injuries. A CTA, performed to determine brain perfusion, yielded a 'false-negative' result. Skull fractures have possibly led to venous prominence in the cortical and deep venous drainage system. This point needs to be borne in mind while considering CTA as an ancillary test to confirm brain death.

\section{BACKGROUND}

Brain death, or the irreversible cessation of function of the brain, is commonly defined by clinical examination. While clinical examination remains the key in determining brain death, and is the accepted method of determining brain death in most countries, there are certain situations when the clinical criteria may not be sufficient and ancillary tests are required. We describe a case of severe traumatic brain injury (TBI) with multiple facial and skull fractures where CT angiogram (CTA) failed to yield a definite result of brain death .Both false-positive and false-negative results are known to happen in this clinical setting. Skull fracture as a reason for false-negative result is something which is not emphasised in the literature. When a similar clinical dilemma is encountered, it is worth considering an alternate ancillary test to confirm brain death, and in case of false-negative result, a meticluous interpretation of the same should be adopted.

\section{CASE PRESENTATION}

A 28-year-old man was admitted following a road traffic accident with a GCS of 3/15 and fixed unreactive $5 \mathrm{~mm}$ pupils. He sustained multiple facial injuries. CT brain revealed multicompartment haemorrhage, right-sided subdural haematoma and extensive subarachnoid haemorrhage as well as diffuse brain swelling (figure 1). CT also revealed multiple skull and facial bone fractures with pneumocephaly, and multiple fractures of the floor and walls of the left orbit (figure 2). An intracranial pressure (ICP) monitor was inserted and monitored in the intensive care unit. His ICP was more than $40 \mathrm{~mm} \mathrm{Hg}$ persistently and refractory to maximal medical management. By day 3 in the ICU, he was

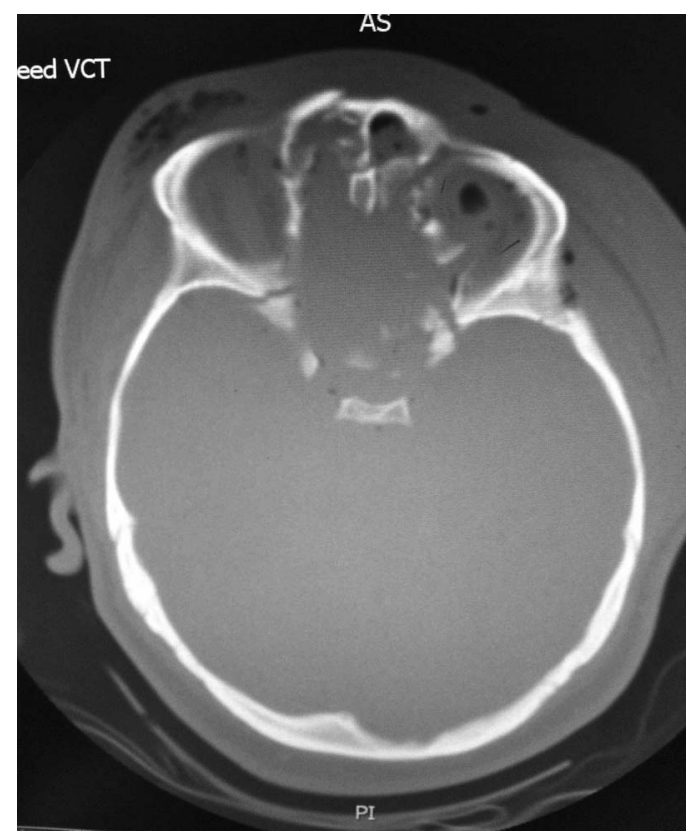

Figure $1 \mathrm{CT}$ non-contrast brain demonstrating diffuse cerebral oedema, thin right subdural haematoma, bifrontal fractures and pneumocephalus and associated subgaleal haematoma.

rewarmed and weaned off all sedation; however, his GCS remained 3/15 and his pupils remained fixed and dilated. Extensive facial injuries made the examination of cranial nerves difficult and clinical tests to confirm brain death were inconclusive.

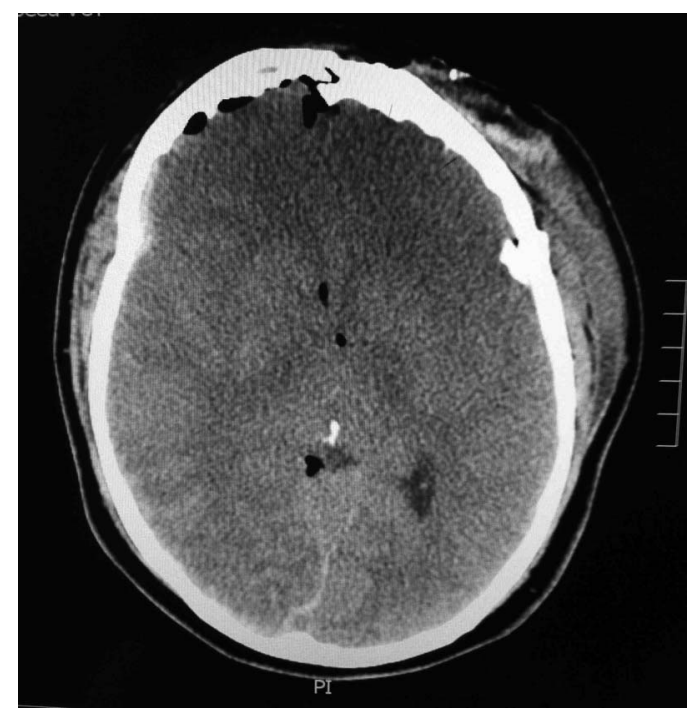

Figure 2 CT bone window demonstrating multiple facial, ethmoidal and sphenoidal fractures. 


\section{INVESTIGATIONS}

Brain stem testing was carried out, which included cranial nerve examination and apnoea test. We experienced difficulty in interpreting the cranial nerves owing to significant periorbital swelling and facial oedema. An ancillary test was considered to confirm brain death. Subsequent CTA revealed enhancement in cortical vessels and deep venous drainage bilaterally, thereby not meeting CTA criteria for brain death (figures 3-5). Carefully considering the CT brain findings, the clinical picture and the 'false-negative' CTA result, the patient was diagnosed to be brain dead and the body was sent for organ harvesting as per the patient's previous wish.

\section{DISCUSSION}

In many countries, clinical testing is considered to be sufficient for confirmation of brain death. However, certain cases may require further testing to determine brain death. A number of confirmatory tests are accepted including EEG, cerebral angiogram, radionuclide angiography and MRI and CTA. For the confirmation of brain death by CTA, a seven-point system is used to evaluate lack of opacifaction of the pericallosal arteries, middle cerebral arteries, internal cerebral vein, basilar artery and great cerebral vein postcontrast injection. CTA, as a method of brain death determination, was validated by Dupas et $a l^{1}$ in 1998 and, on the basis of that study, was accepted as a method of brain death determination in France. A Canadian report in 2008 suggetsed that clinical examination should be performed to the fullest extent possible and that demonstrating absence of brain blood flow by the following techniques fulfil the criteria for ancillary testing: (1) radionulcide angiography or CT angiography; (2) traditional four-vessel angiography; (3) MR angiography or xenon $\mathrm{CT}^{2}$ A further report from Canada in the same year stated that EEG is no longer a recommended tool to assess cerebral perfusion, as reflected by the presence or absence of cerebral blood flow, when clinical assessment is insufficient. ${ }^{3} \mathrm{~A}$ recent study evaluated the sensitivity and specificity of the established seven-point CT angiogram score as well as a novel four-

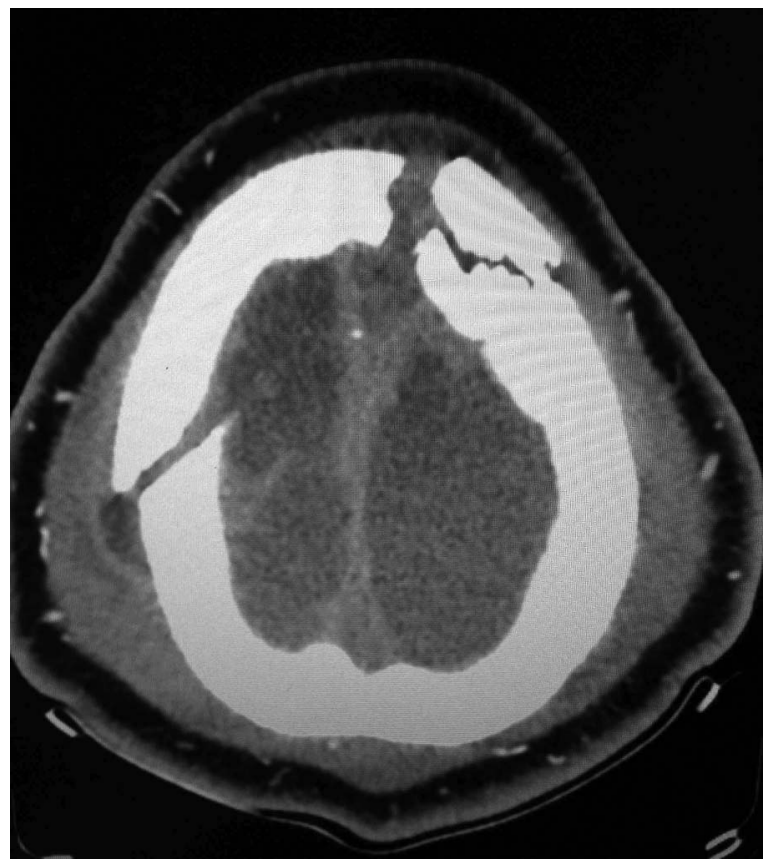

Figure $3 \mathrm{CT}$ angiogram axial view demonstrating blood flow in the cortex and sagittal sinus and associated frontal skull fractures.

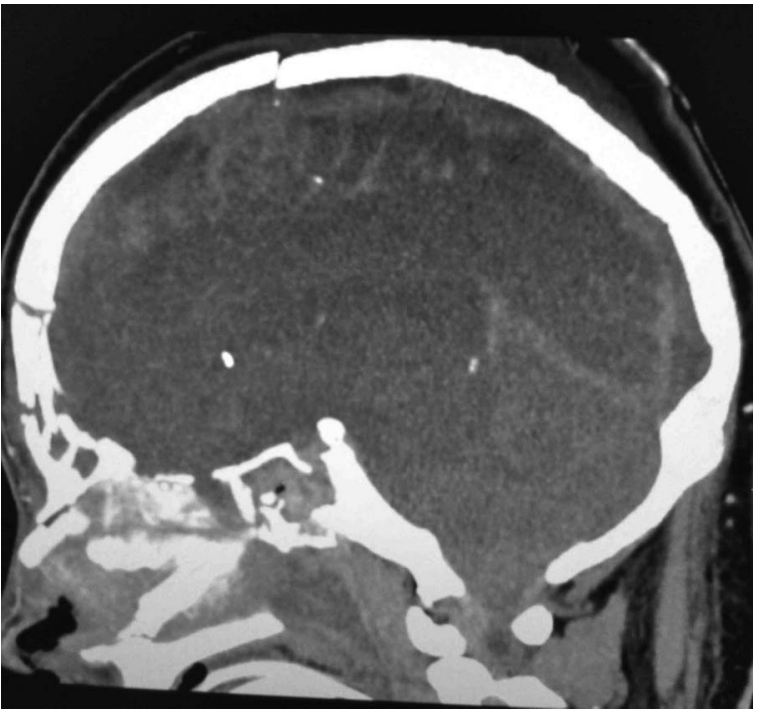

Figure $4 \mathrm{CT}$ angiogram sagittal view demonstrating blood flow in the cortical veins and sagittal sinus and associated frontal skull fracture and facial injury.

point score based on lack of opacification of the cortical segments of the middle cerebral artery (MCAs) and internal cerebral vein (ICVs) evaluating 105 patients with clinically diagnosed brain death. ${ }^{4}$ Results showed a sensitivity of $62.8 \%$ with the seven-point score, and a sensitivity and specificity of $85.7 \%$ and $100 \%$, respectively, with the four-point score. ${ }^{4}$ The authors comment that the abscence of the ICV also appears to be the most sensitive and earliest sign. ${ }^{4}$ In our case, CTA revealed opacification in the cortical surface and in the hemispheres suggestive of cerebral perfusion, contrary to the true clinical picture. We obtained a score of two on a seven-point score and four-point score for our case, as summarised in table 1 .

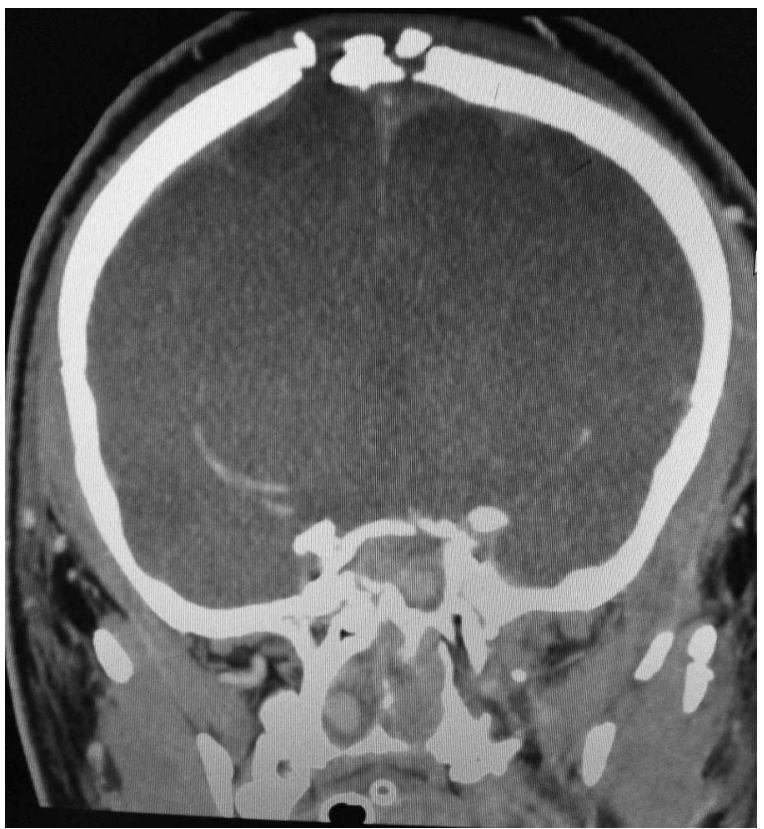

Figure $5 \mathrm{CT}$ angiogram coronal view demonstrating contrast activity in the middle cerebral arteries bilaterally and also in the terminal cortical branches. 
Table 1 Summary of comparison of radiological scores on CTA

\begin{tabular}{|c|c|c|}
\hline $\begin{array}{l}\text { CT angiogram } \\
\text { score types }\end{array}$ & Standard scores & Scores in index case \\
\hline 7-point score ${ }^{1}$ & $\begin{array}{l}\text { Left and right pericallosal } \\
\text { arteries (2) } \\
\text { Left and right middle } \\
\text { cerebral arteries (2) } \\
\text { Left and right internal } \\
\text { cerebral veins (2) } \\
\text { Great cerebral vein of } \\
\text { Galen (1) }\end{array}$ & $\begin{array}{l}\text { Terminal MCA branches } \\
\text { bilaterally (2) }\end{array}$ \\
\hline 4-point score ${ }^{3}$ & $\begin{array}{l}\text { Left and right middle } \\
\text { cerebral arteries }(2) \\
\text { Left and right internal } \\
\text { cerebral veins ( } 2 \text { ) }\end{array}$ & $\begin{array}{l}\text { Terminal MCA branches } \\
\text { bilaterally (2) }\end{array}$ \\
\hline
\end{tabular}

We believe that the presence of multiple skull and facial fractures contributed to persistent cerebral cortical blood flow owing to cerebral decompression, allowing the vasculature to show pseudoactivity and hence a false-negative CTA. This point needs to be remembered while interpreting the CTA in the context of traumatic brain injury with multiple skull fractures.

Cerebral angiogram remains the gold standard test for demonstrating the cerebral vasculature; however, CTA is used as an adjunct or a screening tool due to the ease of performing one and owing to its availability. Studies recently have revealed that sensitivity and specificity were higher than previously reported, suggesting that CTA may be used as an initial screening tool in lieu of DSA in case of detection of intracranial aneurysms in subarachnoid haemorrhage. ${ }^{5}$ One can argue to extend the benefit of utilising CTA in our clinical scenario of demonstrating activity in the cerebral vasculature in a patient with traumatic brain injury as well. In our case, we did not proceed with the cerebral angiogram because of the false-negative result.

\section{'False-negative' CTA and use of ancillary tests}

CTA is an acceptable and technically easier modality to confirm absence of cerebral blood flow. However, the presence of multiple skull fractures led to prominent cortical veins and deep venous drainage. This is something which is not highlighted in the literature. 'False-positive' results are known to occur from the study by Frampas et al. ${ }^{6}$

Muscle relaxants, hypothermia, reversible endocrine, circulatory and metabolic abnormalities must be ruled out at the time of brain death testing. The ancillary tests commonly used as adjuncts to aid the diagnosis are

- In case of false-positive or false-negative CTA, cerebral angiogram can be used to demonstrate flow void in the cerebral vasculature. CTA is much easier to perform and the literature also favours CTA for confirmation of brain death. ${ }^{3}$

- CT perfusion scan.

- MR angiography or Xenon CT as described above.

- Transcranial Doppler (TCD)—absence of Doppler signals or small peaks in early systole without diastolic or reverberating flow (suggestive of increased intracranial pressure).

- EEG-absence of electrical activity. These are less favoured. ${ }^{3}$ Neurophysiology to test brain stem somatosensory evoked potentials (SSEPs) can also be carried out to aid the diagnosis.

To conclude, CTA can be effectively used to confirm brain death. One should be careful in interpreting the results and, if necessary, further ancillary tests need to be performed to establish the diagnosis of brain death if clinical diagnosis is uncertain.

\section{Learning points}

Skull fractures can be a reason for false-negative CT angiogram (CTA) in failed clinical assessment on brain death confirmation.

- Four-point assessment can be successfully used to demonstrate brain death by CTA

- 'False-negative' result from CTA may affect the duration and continuity of intensive care in an otherwise brain-dead individual.

- Ancillary tests-radiological (cerebral angiogram, MR angiogram or xenon CT, transcranial Doppler) and neurophysiological (Evoked potential) can be used to confirm brain death.

\section{Competing interests None.}

Patient consent Obtained.

Provenance and peer review Not commissioned; externally peer reviewed.

\section{REFERENCES}

1 Dupas B, Gayet-Delacroix M, Villiers D, et al. Diagnosis of brain death using two-phase spiral CT. Am J Neuroradiol 1998;19:641-7.

2 Shemie SD, Lee $D$, Sharpe $M$, et al. Brain blood flow in the neurological determination of death: Canadian expert report. Can J Neurol Sci 2008;35:140-5.

3 Frampas $\mathrm{E}$, Videcoq $\mathrm{M}$, de Kerviler $\mathrm{E}$, et al. CT angiography for brain death diagnosis. Am J Neuroradiol 2009;30:1566-70.

4 Heran MK, Heran NS, Shemie SD. A review of ancillary tests in evaluating brain death. Can J Neurol Sci 2008;35:409-19.

5 Prestigiacomo CJ, Sabit A, He W, et al. Three dimensional CT angiography versus digital subtraction angiography in the detection of intracranial aneurysms in subarachnoid hemorrhage. J Neurointerv Surg 2010;4:385-9.

6 Greer D, Strozyk D, Schwamm L. False positive CT angiography in brain death. Neurocritical Care 2009;11:272-5. 
Copyright 2013 BMJ Publishing Group. All rights reserved. For permission to reuse any of this content visit http://group.bmj.com/group/rights-licensing/permissions.

BMJ Case Report Fellows may re-use this article for personal use and teaching without any further permission.

Become a Fellow of BMJ Case Reports today and you can:

- Submit as many cases as you like

- Enjoy fast sympathetic peer review and rapid publication of accepted articles

- Access all the published articles

- Re-use any of the published material for personal use and teaching without further permission

For information on Institutional Fellowships contact consortiasales@bmjgroup.com

Visit casereports.bmj.com for more articles like this and to become a Fellow 